\section{SAT0508 LACK OF A CLEAR DISEASE MODIFYING ACTIVITY OF CELECOXIB IN TREATMENT OF END-STAGE KNEE OSTEOARTHRITIS: A RANDOMIZED OBSERVER BLINDED CLINICAL TRIAL}

E.M. Van Helvoort ${ }^{1}$, K. Coeleveld ${ }^{1}$, T.N. de Boer ${ }^{1}$, A.M. Huisman ${ }^{2}$, A.A. Polak ${ }^{3}$, J.W.J. Bijlsma ${ }^{1}$, J.M. van Laar ${ }^{1}$, F.J.P.G. Lafeber ${ }^{1}$, S.C. Mastbergen ${ }^{1}$.

${ }^{1}$ Rheumatology and Clinical Immunology, University Medical Centre Utrecht, Utrecht; ${ }^{2}$ Rheumatology; ${ }^{3}$ Orthopedics, Sint Franciscus Gasthuis, Rotterdam, Netherlands

Background: Several studies suggest that celecoxib has beneficial effects on degenerated cartilage $(1,2)$. Together with effects on synovial tissue and bone, celecoxib was postulated to have disease modifying osteoarthritic drug (DMOAD) activity.

Objectives: This study evaluated the DMOAD activity of celecoxib, a selective cyclooxygenase 2 (COX-2) inhibitor compared to no treatment and naproxen, treating end-stage knee osteoarthritis $(\mathrm{OA})$, after in vivo exposure using detailed ex vivo tissue analyses.

Methods: 172 patients with end-stage knee OA were randomized to 4 groups and treated for 4 weeks prior to knee replacement surgery: celecoxib 2dd200g, naproxen $3 \mathrm{dd} 250 \mathrm{mg}$, celecoxib $2 \mathrm{dd} 200 \mathrm{mg}$ stopped 3 days prior to surgery, or no treatment. To determine if treatment had reached the joint, intra-articular COX-2 expression was determined by Western Blot analysis in the celecoxib until surgery and no treatment group, considering these as most extremes. Proteoglycan release, as primary outcome and content were determined by staining and precipitation of glycosaminoglycans (GAGs) with Alcian Blue. Release of newly formed proteogylcans, as a measure of proteoglycan retention, was determined by loss of ${ }^{35} \mathrm{SO}_{4}^{2}$-labeled GAGs in culture medium by precipitation of GAGs and subsequent liquid scintillation analysis. Synovial tissue inflammation markers interleukin-1 $\beta$ (IL-1 $\beta)$ and tumor necrosis factor- $\alpha$ (TNF- $\alpha$ ) were determined by Enzyme Linked Immuno Sorbet Assay (ELISA) and nitric oxide (NO) production by standard Griess reaction. Western Ontario and McMaster University (WOMAC) questionnaire was used to evaluate clinical parameters.

Results: Intra-articular COX-2 expression was significantly decreased in both cartilage and synovial tissue (figure 1) indicating proper in vivo exposure of the treatment.

Despite this reduction, no significant effect on proteoglycan release, retention or content was found for none of the treatment groups (table 1). Synovial tissue showed only a small decrease in nitric oxide levels in celecoxib treated patients. No clear clinical effects could be observed as indicated by the WOMAC scores.
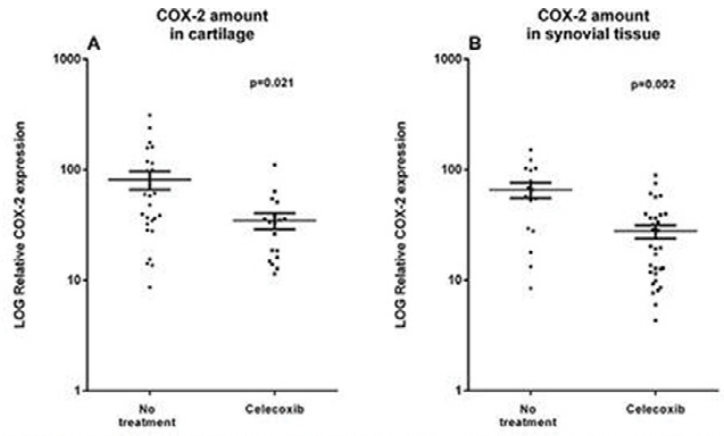

Figure 1. Intra-articular amount of $\mathrm{COX}-2$. The COX-2 levels in cartilage (A) and synovial tissue (B) of the no treatment group and celecoxib until surgery group. Results are presented for each individual patient (dots) and mean \pm SEM (dash with whiskers). P. values are given for celecoxib treated group compared to no treatment group. Due to limited amount of tissue arailable the analyses of cox-2 for cartilage was limited to 18 treated and 25 non-treated patients and for symovial tissue to 31 treated and 16 non-treated patients

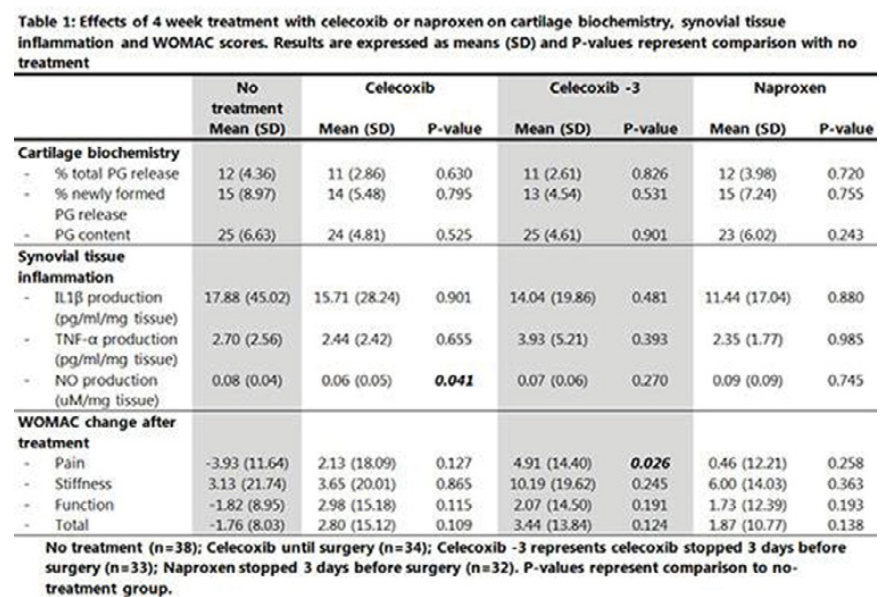

Conclusions: No effect of a 4-week in vivo celecoxib treatment on joint tissue in knee OA patients could be detected, although decreased expression of COX-2 confirmed its intra-articular availability. Effects on synovial inflammatory mediators and clinical outcome were very limited. No adverse effects were found either. As such the previous reported disease modifying effects of celecoxib in in vitro and pilot clinical studies could not unambiguously be confirmed in this randomized trial. References:

[1] de Boer TN, Huisman AM, Polak AA, Niehoff AG, van Rinsum AC, Saris D, et al. The chondroprotective effect of selective COX-2 inhibition in osteoarthritis: ex vivo evaluation of human cartilage tissue after in vivo treatment. Osteoarthritis and cartilage/OARS, Osteoarthritis Research Society. 2009;17(4):482-8.

[2] Mastbergen SC, Jansen NW, Bijlsma JW, Lafeber FP. Differential direct effects of cyclo-oxygenase-1/2 inhibition on proteoglycan turnover of human osteoarthritic cartilage: an in vitro study. Arthritis research \& therapy. 2006;8(1):R2.

Disclosure of Interest: E. Van Helvoort: None declared, K. Coeleveld: None declared, T. de Boer: None declared, A. Huisman: None declared, A. Polak: None declared, J. Bijlsma Grant/research support from: J.W.J. Bijlsma received a consultancy fee from Pfizer (<5.000 US\$). J. van Laar: None declared, F. Lafeber: None declared, S. Mastbergen: None declared

DOI: 10.1136/annrheumdis-2017-eular.1454

\section{SAT0509 DYNAMICS IN THE LEVELS OF ADIPOKINES AND CYTOKINES IN PARALLEL WITH WEIGHT LOSS AND THEIR RELATIONSHIP WITH CLINICAL MANIFESTATIONS OF KNEE OSTEOARTHRITIS}

E. Strebkova ${ }^{1}$, I. Solovyova ${ }^{2}$, A. Mkrtumyan ${ }^{2}$, L. Alekseeva ${ }^{1} .{ }^{1}$ Nasonova Research Institute of Rheumatology; ${ }^{2}$ Moscow State Medical Stomatological Institute, Moscow, Russian Federation

Background: Untoward effects of pro-inflammatory cytokines on a chondrocyte are implied in pathogenesis of osteoarthritis $(\mathrm{OA})$, while adipokines would enhance these pathogenetic mechanisms and facilitate maintenance of inflammation and progression of OA when the latter is associated with obesity.

Objectives: To asses dynamic changes of adipokine (leptin) and pro-inflammatory cytokines (IL-6, TNF- $\alpha$ ) levels and their relationship with clinical manifestations of knee OA in pts losing weight during orlistat therapy.

Methods: The study included 50 female pts aged 45-65 years with knee OA Kellgren-Lawrence stage II-III, and obesity $\left(\mathrm{BMI}>30 \mathrm{~kg} / / \mathrm{m}^{2}\right)$. Pts form Group 1 $(n=25)$ were receiving orlistat $120 \mathrm{mg} \times 3$ times a day for 6 month combined with low-caloric diet and therapeutic physical exercise. Pts from Group $2(n=25)$ were administered only low-caloric diet and therapeutic physical exercise for 6 month. Anthropometry data (height, body weight, BMI), WOMAC and quality of life EQ-5D scores, as well as serum levels of leptin, IL-6 and TNF- $\alpha$ using ELISA were assessed at baseline and at 6 months in all pts.

Results: Following pharmacological and non-pharmacological therapy of obesity in pts with knee OA subjects from Group 1 reduced their body weight by $10,07 \%$ $(p<0,05)$, and pts from Group 2 - by $0,84 \%(p>0,05)$. At baseline pts from both groups did not differ $(p>0,05)$ by leptin, IL-6 and TNF- $\alpha$ levels. Decreased leptin levels were documented in pts from Group 1 after 6 months of orlistat therapy $(p=0,05)$, which directly correlated with body weight loss $(r=0,5, p=0,02)$, total WOMAC score reduction $r=0,5, p=0,01$ ), and score reduction in WOMAC subscales measuring pain $r=0,5, p=0,01$; stiffness $r=0,4, p=0,04$; and functional insufficiency $r=0,4, p=0,03$, thus reflecting improvement of $O A$ symptoms; and inversely correlated with increased EQ-5D score $(r=-0,4, \quad p=0,03)$ reflecting improvement in quality of life. Besides, orlistat therapy was associated with decreased IL-6 levels $(p<0,05)$. Both groups demonstrated high TNF- $\alpha$ levels, although some insignificant decrease was noticed in Group $1(p=0,14)$ following weight loss with orlistat therapy. Persisting leptin, IL-6 and TNF- $\alpha$ levels were registered in pts from Group 2, who maintained their body weight following only life-modifying therapy of obesity. Clear correlations between IL- 6 and TNF- $\alpha$ levels and changes in body weight and clinical manifestations of OA were not found in both groups.

Conclusions: Significant decrease in leptin and IL-6 levels were observed in knee OA pts following orlistat therapy and associated weight loss. There was a direct correlation between decreased leptin levels and body weight loss, as well as reduction in WOMAC scores reflecting improvement of knee OA clinical manifestations, and inverse correlation with EQ-5D score resulting in quality of life improvement. Therefore, body weight loss following pharmacotherapy of obesity is associated not only with improvement of OA clinical symptoms, but also with down-regulation in production of pro-inflammatory leptin and IL-6, most probably resulting in reduction of meta-inflammation in obese pts with $O A$.

Disclosure of Interest: None declared

DOI: 10.1136/annrheumdis-2017-eular.2822

\section{SAT0510 EFFECT OF PHARMACOLOGICAL AND NON-PHARMACOLOGICAL THERAPY OF OBESITY ON THE CLINICAL MANIFESTATIONS OF OSTEOARTHRITIS}

E. Strebkova, L. Alekseeva. Nasonova Research Institute of Rheumatology, Moscow, Russian Federation

Background: Osteoarthritis $(\mathrm{OA})$ and obesity are inter-related and most challenging conditions for the public health, leading to significant deterioration in quality of 